\title{
Augmented Reality Chemical Reaction with User-Centered Design
}

\author{
Finsa Nurpandi $^{{ }^{*}}$, and Agung Gumelar ${ }^{l}$ \\ ${ }^{l}$ Informatics Engineering Program, Faculty of Engineering, Suryakancana University, Indonesia.
}

\begin{abstract}
One of chemistry is the chemical element that is represented by the symbol on the periodic table. The low level of activity, interest, and the result of chemistry learning in school is caused by the students generally having difficulty in solving problems related to chemical reactions. In addition, most of the chemical concepts are abstract so it is difficult to imagine the structure of molecules clearly. Augmented Reality can integrate digital elements with the real world in real time and follow the circumstances surrounding environment. Augmented Reality can provide a new more interactive concept in the learning process because users can directly interact naturally. By using Augmented Reality, the atoms in the periodic table will be scanned using a camera from an Android-based smartphone that has installed this app. The scan results are then compared with existing data and will show the molecular structure in threedimensional form. Users can also observe reactions between atoms by combining multiple markers simultaneously. Augmented Reality application is built using the concept of user-centered design and Unity with personal license as development tools. By using this app, studying chemical reactions no longer requires a variety of chemicals that could be harmful to users.
\end{abstract}

\section{Introduction}

Augmented Reality (AR) is a technology where there is integration between digital elements with the real world in real time and follow the circumstances surrounding environment. Azuma [1] proposes augmented reality as the incorporation of real and virtual objects in real environment that runs interactively in real time, where virtual objects are integrated in the real world. The basic concept of Augmented Reality is to take objects or elements in the real world as a base (marker) using the base image, then add a virtual element to be accepted by the user. This virtual element can be text, audio, visual, or any other form. Many of the benefits of the development of Augmented Reality that can be applied to various human activities, especially in the field of education. This is because Augmented Reality technology can provide a new way more interactive in the learning process because users can directly interact naturally.

One of the materials in chemistry is the chemical elements depicted using symbols in the periodic table. The use of this symbol is due to the chemical elements can't be observed

\footnotetext{
*Corresponding author: finsa@unsur.ac.id
} 
using the senses. Based on research by Sunyono [2] in 2005, low activity, interest, and low student's chemistry result is caused by the general difficulties in solving problems related to chemical reaction and chemical count. This shows that chemistry is difficult to learn, one of which is because most of the chemical concepts themselves are abstract and learners can't imagine the molecular structure clearly. Chemical practice conducted in schools can't be done optimally, because it requires a long time of preparation in a limited time, so that student learning time can't be utilized optimally. Expenditure of funds large enough for each lab also became one of the reasons lab chemistry in school is not optimal. Some of the substances that are harmful to students also become one of the problems that arise if the chemistry lab is not supervised by experts.

By using AR, the atoms in the periodic table will be scanned using the device in this case is the camera, then will be compared with the existing data in the application and bring up the molecular structure in $3 \mathrm{D}$ form. Users can also observe the reaction between atoms by combining multiple markers at once. Making this application itself using Unity with personal license and Vuforia Software Development Kit (SDK). Using this app, to learn about chemical reactions does not require expensive and dangerous equipment and lab materials, ordinary people can learn chemical reactions only with the help of android-based smartphones and cards that serve as markers.

\section{Related Work}

According to Banu [3] and Purnama [4] in their work that made AR based Geometry learning system. Banu explained that the system he developed would produce 3D geometry objects derived from 2D geometry handwritten. While Purnama made an AR system specifically intended for elementary school as a learning process in understanding geometry.

Martinez [5] and Lee [6] in their work made a lesson to improve of using vocabulary and grammatical structures for English using AR technology.

The AR system developed by Nanthanasit [7] is a system for learning art. The system will explain how light reacts to objects such as sphere, cylinder, and cube. While based on what was done by Chen [8], is an AR system that is used to display a graphical representation of engineering structure.

\section{Methodology}

This application was developed using Multimedia Development Life Cycle (MDLC) model. As shown in Fig 1, Binanto [9] describes a software development model derived from Luther [10] consisting of six stages: concept, design, collecting material, assembly, testing, and distributing. This software development model is intended for multimedia development.

The concept stage is the initial stage to determine the type of application and purpose for which the application is made. The next stage, design, make specifications about the program architecture, style, appearance, and material needs. Material collecting is the stage by which the collection of materials matches the need. This stage can be done parallel to the assembly stage, the stage where all objects or multimedia materials are created. In some cases, the material collecting stage and assembly stage will be worked out in a linear fashion not parallel. The testing phase is also referred to as the alpha test stage (alpha test) where the test is performed by the manufacturer or the manufacturer's own environment. This last stage will store multimedia applications in a storage medium and distribute it. 


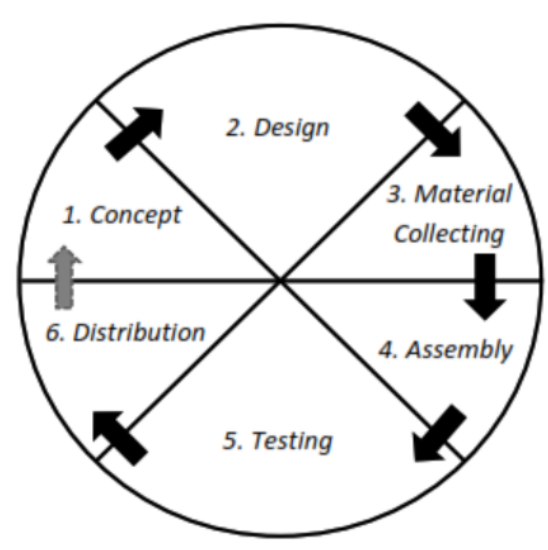

Fig. 1. MDLC Process

\section{Design System}

\subsection{Use Case}

In this system, there are two actors namely User and Camera. Users are represented as people who operate the system, and the camera as a device that interacts with markers. As shown in Fig 2, there are four Use Cases in this system. Users can scan markers and view a list of existing chemical reactions and view application info, and the camera can identify the markers that were previously directed by the user.

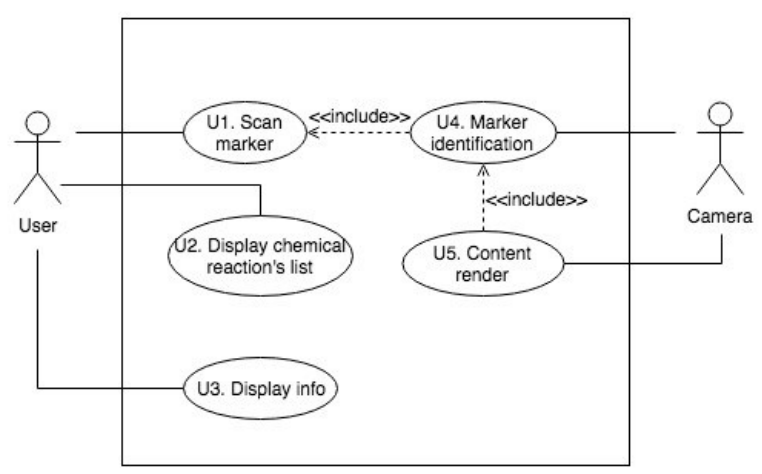

Fig. 2. Use Case Diagram

\subsection{Activity Diagram}

The Activity diagram as shown in Fig 3, describes the entire process of the Augmented Reality Chemical Reaction system. In the process User is given three menu options, namely menu Scan, Minipedia, and Info. Scan menu is the main process of this system. The system will scan the marker that has been given. When identifying the marker, the system will check whether the marker is in the library or not. The library marker is stored in the Vuforia SDK, which previously the marker image must be uploaded to Vuforia SDK. If yes, then the system will display $3 \mathrm{D}$ objects and their chemical reactions. 
The Minipedia and Info menu displays only available chemical reaction information and information about the application developer. Chemical reactions contained in Minipedia is a chemical reaction that can be obtained from the scanned Marker. In a sense, the number of chemical reactions in Minipedia is equal to the number of markers that can be scanned.

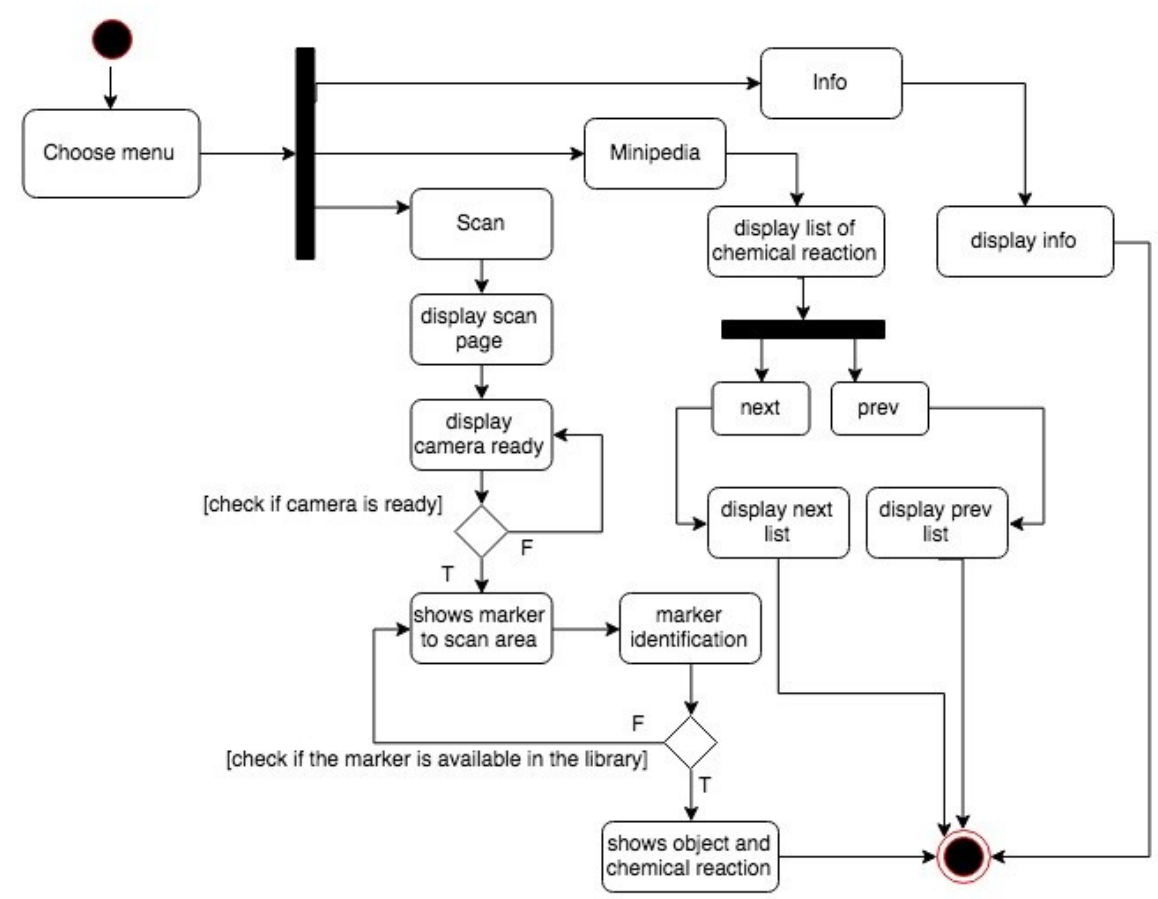

Fig. 3. Activity Diagram

\subsection{Class Diagram}

In this stage, classes will be created in the structure of the program, in which there are inputs, processes, outputs and data. Each class will connect with other classes or with attributes of other classes. In this stage, it takes a Class Diagram to be used as a blueprint or design for the structure of the program to be created.

Based on Fig 4, Class Diagram Augmented Reality Chemical Reaction application can be known relation of all existing classes in the system, Content class has a relationship composition with Scan class, this is because the class has a dependence on the Scan class. Scan class has associate relationship with Menu class. Menu class associated with the Minipedia class. 


\begin{tabular}{|c|c|c|}
\hline Scan & \multirow[b]{2}{*}{$1 . *^{*}$} & Menu \\
\hline \multirow{2}{*}{$\begin{array}{l}\text { - Layout: camera } \\
\text { - Marker: image } \\
\text { - Content: content[] } \\
\text { - Button1: back }\end{array}$} & & \multirow{3}{*}{$\begin{array}{l}\text { - Layout: MainMenu } \\
\text { - Title: Image } \\
\text { - Button1: Scan } \\
\text { - Button2: Minipedia } \\
\text { - Button3: Info } \\
\text { - Sound: audio }\end{array}$} \\
\hline & doing 1 & \\
\hline \multirow{2}{*}{$\begin{array}{l}\text { + onStart() } \\
\text { + onUpdate() } \\
\text { + checkMarker() } \\
\text { + checkCamera() }\end{array}$} & & \\
\hline & & \multirow{2}{*}{$\begin{array}{l}\text { + onStart0) } \\
\text { + goToScene() } \\
\text { + showlnfo() }\end{array}$} \\
\hline & & \\
\hline$Y_{\text {display }}$ & & \begin{tabular}{l|l}
1 \\
display
\end{tabular} \\
\hline 1.2 & & $1 . *^{*}$ \\
\hline \multicolumn{2}{|l|}{ Content } & Minipedia \\
\hline $\begin{array}{l}\text { - Marker: Image } \\
\text { - Content: Object3d } \\
\text { - Chemistry: int } \\
\text { - Sound: audio }\end{array}$ & & \multirow{2}{*}{$\begin{array}{l}\text { - Layout: Minipedia } \\
\text { - ContentNo: int } \\
\text { - Content: Image } \\
\text { - Desciption: Text } \\
\text { - Button1: Prev } \\
\text { - Button2: Next }\end{array}$} \\
\hline \multirow{2}{*}{$\begin{array}{l}\text { + getContent() } \\
\text { + checkReact() } \\
\text { + setReact() } \\
\text { + audioPlay() }\end{array}$} & & \\
\hline & & $\begin{array}{l}\text { + onStart() } \\
+ \text { loadSlide() } \\
+ \text { onClick() }\end{array}$ \\
\hline
\end{tabular}

Fig. 4 Class Diagram

\section{Result}

In the selection of the initial interface, the use of less-bright colors and easily readable fonts is generally suitable for the user, the selection of instrumental music can also be used to avoid boredom. For the interface design is obtained as follows:

a. Use blue as the background colour of the app, because blue represents innovation, knowledge.

b. Use bright colors like red and yellow to attract user attention or warning.

c. Use a small amount of color so that users do not feel confused with the number of colors.

d. Use Bebas Neue fonts, because in this chemical simulation media application is required is the ease of users in reading and understanding writing, not the beauty of shapes and colors.

The interface of the AR Chemical Reaction application can be viewed as in Fig 5 .

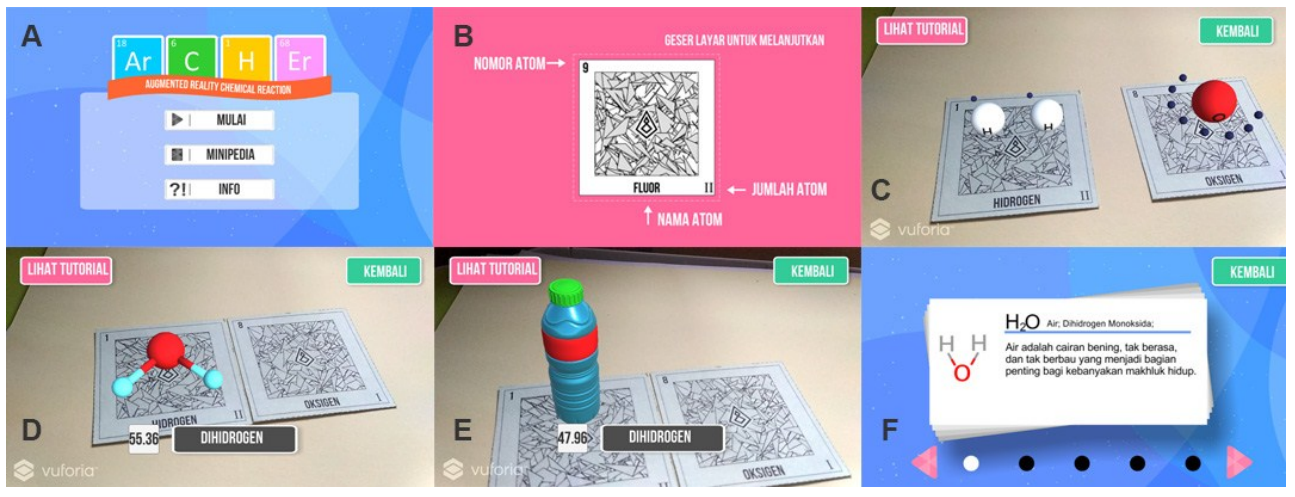

Fig. 5. Interface of AR Chemical Reaction, (A) Main Menu, (B) Tutorial scan marker, (C) Scan marker, (D) Scan with combine marker, (E) Scan combine marker with object $<50$ from camera, (F) Minipedia page 


\section{Conclusion}

AR Chemical Reaction application serves as a simulation media of chemical reactions that can be used by students, teacher, and the general public. Inside the user can see a list of chemical reactions and can perform simulations of basic chemical reactions. For its development, some features can be added to this app. Such as adding a quiz feature to guess and calculate the chemical reaction of a given problem.

\section{References}

1. R. T. Azuma, "A Survey of Augmented Reality Navigation," Presence Teleoperators Virtual Environ., vol. 6, no. 4, pp. 355-385, 1997.

2. Sunyono, Optimalisasi Pembelajaran Kimia Kelas IX Semester I SMA. 2005.

3. S. M. Banu, "Augmented reality system based on sketches for geometry education," 2012 Int. Conf. E-Learning E-Technologies Educ. ICEEE 2012, pp. 166-170, 2012.

4. J. Purnama, D. Andrew, and M. Galinium, "Geometry Learning Tool for Elementary School using Augmented Reality," Iaict, no. August, pp. 145-148, 2014.

5. A. A. Martinez, J. R. L. Benito, E. A. Gonzalez, and E. B. Ajuria, "An experience of the application of Augmented Reality to learn English in Infant Education," 2017 Int. Symp. Comput. Educ. SIIE 2017, vol. 2018-January, pp. 1-6, 2018.

6. L.-K. Lee, C.-H. Chau, C.-H. Chau, and C.-T. Ng, "Using Augmented Reality to Teach Kindergarten Students English Vocabulary," 2017 Int. Symp. Educ. Technol., pp. 53-57, 2017.

7. A. Nanthanasit and N. Wongta, "Approach augmented reality real-time rendering for understanding light and shade in art education," 3rd Int. Conf. Digit. Arts, Media Technol. ICDAMT 2018, pp. 71-74, 2018.

8. H. Chen, K. Feng, C. Mo, S. Cheng, Z. Guo, and Y. Huang, "Application of augmented reality in engineering graphics education," ITME 2011 - Proc. 2011 IEEE Int. Symp. IT Med. Educ., vol. 2, pp. 362-365, 2011.

9. I. Binanto, Multimedia Digital Dasar Teori dan Pengembangannya. Yogyakarta: Andi, 2010.

10. L. A. C, Authoring Interactive Multimedia. Massachusettes: Academic Press, Inc, 1994. 